\title{
Blood pressure and BMI in adolescents in Aracaju, Brazil
}

\author{
Jorinde Polderman ${ }^{1}$, Ricardo Queiroz Gurgel ${ }^{2}$, José Augusto S Barreto-Filho², \\ Rik Roelofs ${ }^{1}$, Ricardo Emanoel de $\bigcirc$ Ramos $^{2}$, Jeroen S de Munter ${ }^{1}$, \\ Johannes F Wendte ${ }^{1}$ and Charles Agyemang ${ }^{1, *}$ \\ 'Department of Public Health, Academic Medical Centre, University of Amsterdam, Meibergdreef 9, 1105 AZ \\ Amsterdam, The Netherlands: ${ }^{2}$ Department of Medicine and Post Graduate Nucleus of Medicine, Federal \\ University of Sergipe, Aracaju, Brazil
}

Submitted 8 March 2010: Accepted 2 December 2010: First published online 3 February 2011

\begin{abstract}
Objective: To assess the prevalence of high blood pressure (BP) and the association of overweight and obesity with high BP among adolescents in Aracaju, Brazil.

Design: Cross-sectional study. The main outcome measure was the proportion of adolescents with high BP (sex-, age- and height-specific $\geq 95$ th percentile). The main predictor variables were overweight and obesity defined according to the criteria of the International Obesity Task Force. Other covariates included age, socio-economic status and leisure-time physical activity.

Setting: Aracaju, Brazil, capital city of Sergipe State, north-eastern Brazil.

Subjects: A random sample of 1002 adolescents (442 boys and 560 girls) aged 12-17 years selected from twenty public schools and ten private schools were studied.

Results: The prevalence of high BP was $16 \cdot 9 \%$ (95\% CI 13.1, 21.7) in boys and $12 \cdot 9 \%(95 \%$ CI $9 \cdot 0,18 \cdot 0)$ in girls. After adjusting for age, socio-economic status and leisure-time physical activity in both boys and girls, overweight (prevalence ratio $(\mathrm{PR})=1 \cdot 93,95 \% \mathrm{CI} 1 \cdot 08,3 \cdot 48 ; \mathrm{PR}=4 \cdot 34,95 \% \mathrm{CI} 2 \cdot 58,7 \cdot 30$, respectively) and obesity $(\mathrm{PR}=4 \cdot 87,95 \% \mathrm{CI} 2 \cdot 35,10 \cdot 11 ; \mathrm{PR}=5 \cdot 18,95 \%$ CI $2 \cdot 67,10 \cdot 06$, respectively) were found to be associated with high $\mathrm{BP}$.

Conclusions: These findings indicate a high prevalence of high BP in both boys and girls in Aracaju, Brazil. Overweight and obesity were strongly associated with high BP. These findings underscore the urgent need for public health measures to prevent increasing high BP in adolescents in Brazil. Targeting intervention in adolescence may be a critical method for preventing high BP in later life.
\end{abstract}

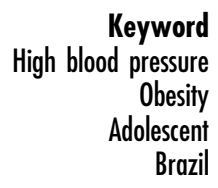

Hypertension has been identified as one of the leading causes of CVD and premature mortality in the world ${ }^{(1,2)}$. In the past few decades, the prevalence of hypertension has increased dramatically worldwide ${ }^{(2-4)}$. In Brazil, for example, hypertension prevalence has increased substantially to as high as $33 \%$ in Aracaju among adults aged $\geq 18$ years $^{(5,6)}$. The rising prevalence of hypertension in Brazil reflects well on the high prevalence of CVD. IHD (25\% of total deaths) and cerebrovascular diseases (34\%) are the leading causes of mortality in Brazil ${ }^{(7)}$.

In children, blood pressure (BP) tracking patterns confirm that persistent $\mathrm{BP}$ increase may be related to hypertension in adulthood ${ }^{(8,9)}$. Increased BP in childhood has also been linked to left ventricular hypertrophy ${ }^{(10)}$. As a result, detection and management of high $\mathrm{BP}$ at an early age may be an important approach for limiting the disease burden ascribed to high $\mathrm{BP}^{(11)}$.
The prevalence of high BP in children in Western countries ranges from $7 \%$ to $19 \%$ on the basis of measurements taken on one visit $^{(12-14)}$. In contrast, few population-based studies have been conducted in children and adolescents in middle- and low-income countries $^{(15-22)}$. Continuous assessment of high BP in children is relevant for health-care policy and prevention strategies.

Furthermore, childhood obesity has increased considerably over the past few decades. Many studies have shown that overweight and obesity are associated with $\mathrm{BP}$ in children and adolescents ${ }^{(2,3,23-25)}$. In the USA, for example, overweight children have been shown to be two to four times more likely than non-overweight children to have high $\mathrm{BP}^{(3)}$. However, information on the relationship between body size and high BP in children and adolescents in non-Western countries is limited. In addition, some studies suggest that BP levels in children 
have recently increased in parallel to the obesity epidemic $^{(2,26)}$. Other studies, by contrast, have shown that BP levels have decreased over time in spite of upward trends of obesity ${ }^{(27)}$. These findings suggest that the strength of the relationship between BP and body weight in children and adolescents may differ between populations in different settings.

In Brazil, information on high $\mathrm{BP}$ in adolescents is limited $^{(20-22,28)}$. Evidence also suggests that overweight and obesity in children are becoming a major problem in Brazil. The prevalence of overweight and obesity in adolescents has increased dramatically from $4 \cdot 0 \%$ and $8 \cdot 2 \%$ in 1975 to $17 \cdot 9 \%$ and $15.4 \%$ in 2003 in both boys and girls, respectively ${ }^{(29)}$. More recent studies show even higher prevalence rates of overweight and obesity ranging from $24.0 \%$ in São Paulo to $36.9 \%$ in Salvador, Bahia $^{(20,30)}$. Despite the increasing prevalence of overweight and obesity, information on the relationship between body size and high BP in adolescents is limited in Brazil. Therefore, the main aim of the present study was to estimate the prevalence of high BP and the association of overweight and obesity with high BP among adolescents in Aracaju, Brazil.

\section{Methods}

\section{Study area}

The present study was carried out in Aracaju, the capital city of Sergipe State, Brazil. Aracaju is located in the northeastern part of Brazil, about $350 \mathrm{~km}$ north of Salvador. Aracaju has a population of about 544039 inhabitants, which represents approximately $33 \%$ of the state population. Sugar cane and petroleum extraction are its main economic activities. The majority of the population (about three-quarters) is of African descent and of mixed African and Portuguese descent.

\section{Study design}

Data were collected between February and May 2008 from healthy adolescents aged between 12 and 17 years from thirty different schools. The schools were randomly selected from all eighty-one schools (fifty public and thirty-one private schools) in the five districts of Aracaju. According to official statistics, the total number of adolescents (10-18 years of age) in Aracaju is 72 683. For each of the five districts, four public schools and two private schools were randomly selected. The selection of schools in this way allowed us to obtain representative samples of students from different school types and locality. In each school, we randomly selected fifty students among those aged 12-17 years. All the selected students were given an informed consent form to be signed by their parents. Of the 1500 students, 1016 returned the consent form (response rate: $67 \cdot 7 \%$ ). The response rate was relatively similar in both public $(68.0 \%)$ and private $(64.5 \%)$ schools. The 12-year-olds had a lower response rate (57\%) than 13-17-year-olds, ranging from $60 \%$ to $78 \%$. Fourteen adolescents were excluded from the study because they did not meet the age criterion. Ethical approval was obtained from the Research Ethics Committee of the Federal University of Sergipe, Brazil.

\section{Physical measurements}

All measurements were taken in a private room provided by the schools.

\section{Main outcome measure}

The main outcome measure was high $\mathrm{BP}$, which was measured according to the European Society of Hypertension Guidelines ${ }^{(31)}$. BP was measured with a validated oscillometric automated digital BP device (Omron M-6; Omron Healthcare Europe BV, Hoofddorp, The Netherlands) by trained medical students from Aracaju (Brazil) and Amsterdam (The Netherlands). Using appropriate cuff sizes, three readings of 2 min intervals were taken on the right arm in a seated position after at least 5 min rest. The mean of the last two readings was used for analysis. Sex-, age- and height-specific percentile levels were defined using US normative BP tables for children and adolescents $^{(11,32)}$. High BP was defined as systolic BP and/or diastolic $\mathrm{BP} \geq 95$ th percentile ${ }^{(11)}$.

\section{Primary covariate}

The main predictor variables were overweight and obesity. Height was measured without shoes with a measuring tape to the nearest $0.01 \mathrm{~m}$. Weight was measured to the nearest $0 \cdot 1 \mathrm{~kg}$ after removal of shoes, jackets, heavy clothing and pocket contents using a digital Seca scale. BMI was calculated as weight in kilograms divided by the square of height in metres $\left(\mathrm{kg} / \mathrm{m}^{2}\right)$. Overweight and obesity were defined using the sex- and age-specific BMI criteria of the International Obesity Task Force ${ }^{(33)}$.

\section{Other covariates}

In addition, participants were asked to complete a questionnaire including questions on age, sex and physical activity. Physical activity was based on the number of days per week engaged in leisure-time physical activity outside school. The type of school (private or public school) was used as proxy for socio-economic status. Public schools are free of charge, but private schools charge a tuition fee.

\section{Data analysis}

Cross-tabulations were analysed using the $\chi^{2}$ test. Continuous outcome variables were analysed by independent samples $t$ test. Linear regression analyses were used to assess the relationship between overweight and obesity and mean BP. Prevalence ratios (PR) of high BP and their $95 \%$ CI were estimated by means of Poisson regression with robust variance to assess the relationship between 
overweight and obesity and high $\mathrm{BP}^{(34)}$, adjusting for factors that are known to be associated with high BP in adolescents (age, socio-economic status and physical activity) ${ }^{(5,22)}$. The analyses were stratified by sex, because there was a significant interaction between sex and overweight and obesity. $P$ values and 95\% CI were calculated with two-tailed tests with correction for the cluster design effect. All statistical analyses were performed using the STATA statistical software package version $11 \cdot 0$ (StataCorp., College Station, TX, USA).

\section{Results}

\section{Characteristics of the study population}

In Table 1, the characteristics of the study population are shown for boys and girls. Girls were shorter, lighter and had a somewhat higher BMI than boys. Boys were more physically active than girls.

\section{Blood pressure levels and association of overweight and obesity with bigh blood pressure among Aracaju adolescents}

The mean systolic BP was higher but diastolic BP was lower in boys than in girls. The prevalence of high BP was higher in boys than in girls, although the 95\% CI overlapped slightly.

Overweight and obese boys and girls had higher mean systolic and diastolic BP levels compared with their normalweight peers (Table 2). The differences hardly changed after adjusting for type of school and leisure-time physical activity in linear regression models. These differences were observed at all ages for systolic BP (Fig. 1a, b) and diastolic BP (Fig. 2a, b) in both boys and girls, with the systolic BP differences being statistically significant for 14- and 17-yearold boys and for all age groups in girls.

Overweight and obese boys and girls had a higher prevalence of high BP compared with their normalweight peers (Table 3). The differences persisted after adjustments for age, type of school and physical activity: overweight boys ( $\mathrm{PR}=1 \cdot 93,95 \% \mathrm{CI} 1 \cdot 08,3 \cdot 48)$ and obese boys $(\mathrm{PR}=4 \cdot 87,95 \% \mathrm{CI} 2 \cdot 35,10 \cdot 11)$ were more likely than normal-weight boys to have high BP. Overweight girls $(\mathrm{PR}=4 \cdot 34,95 \% \mathrm{CI} 2 \cdot 58,7 \cdot 30)$ and obese girls $(\mathrm{PR}=5 \cdot 18$, $95 \%$ CI $2 \cdot 67,10 \cdot 06)$ also had a higher PR of high BP compared with their normal-weight peers.

\section{Discussion}

\section{Key findings}

We found a high prevalence of high BP in both boys and girls. Overweight and obesity were strongly associated with high BP in both boys and girls.

\section{Discussion of the key findings}

Studies on high BP and association of overweight and obesity with high BP among adolescents are limited in Brazil $^{(22-24)}$. In Guimarães et al.'s ${ }^{(20)}$ study, the prevalence rates of high systolic BP and high diastolic BP were 20.4\% and $17 \cdot 6 \%$, respectively, in Salvador ${ }^{(22)}$. However, high BP was defined as $\geq 90$ th percentile and the analyses were based on boys and girls combined. Guimarães et al.'s ${ }^{(20)}$ study was also conducted in a middle-class neighbourhood in Salvador. Evidence suggests that BP increases with socio-economic status in Brazil ${ }^{(7,24)}$, which may indicate that the results found by Guimarães et al. ${ }^{(20)}$ may not represent the actual prevalence of high BP in children in urban Brazil. Data were collected in all socioeconomic groups in our study and therefore give a better reflection of BP in adolescents in an urban setting in Brazil.

The other studies in Brazil were also based on children or younger adolescents and the results were also reported for boys and girls combined ${ }^{(21,24)}$. Rodrigues et al. studied 10-14-year-olds in Victoria, Espirito Santo ${ }^{(21)}$, and reported a $3 \cdot 4 \%$ rate of high BP among boys and girls combined. Costanzi et $a l^{(22)}$ also studied children aged 7-12 years in Caxias do Sul, State of Rio Grande do Sul, and the rate of

Table 1 Characteristics of the study population of Aracaju adolescents by sex

\begin{tabular}{|c|c|c|c|c|c|}
\hline \multirow[b]{2}{*}{ Characteristic } & \multicolumn{2}{|c|}{ Boys (n 442) } & \multicolumn{2}{|c|}{ Girls (n 560) } & \multirow[b]{2}{*}{$P$ value } \\
\hline & Mean or $\%$ & $95 \% \mathrm{Cl}$ & Mean or \% & $95 \% \mathrm{Cl}$ & \\
\hline Age (years) & $14 \cdot 2$ & $13 \cdot 8,14 \cdot 5$ & $14 \cdot 1$ & $13 \cdot 8,14 \cdot 3$ & 0.292 \\
\hline Number of adolescents attending private school (\%) & $33 \cdot 3$ & $17 \cdot 6,53 \cdot 7$ & $32 \cdot 9$ & $17 \cdot 7,52 \cdot 8$ & 0.906 \\
\hline Leisure-time physical activity $(\mathrm{d} / \text { week })^{\star}$ & $3 \cdot 1$ & $2 \cdot 8,3 \cdot 3$ & $1 \cdot 8$ & $1 \cdot 5,2 \cdot 0$ & $<0.001$ \\
\hline Weight $(\mathrm{kg})$ & $54 \cdot 6$ & $51 \cdot 8,57 \cdot 4$ & $51 \cdot 1$ & $49 \cdot 9,52 \cdot 3$ & 0.004 \\
\hline Height (cm) & $164 \cdot 5$ & $162 \cdot 1,166 \cdot 8$ & $158 \cdot 0$ & $157 \cdot 1,158 \cdot 9$ & $<0.001$ \\
\hline BMI $\left(\mathrm{kg} / \mathrm{m}^{2}\right)$ & $19 \cdot 9$ & $19 \cdot 3,20 \cdot 3$ & $20 \cdot 4$ & $20 \cdot 0,20 \cdot 7$ & 0.058 \\
\hline Overweight (\%) & $12 \cdot 9$ & $9 \cdot 7,16 \cdot 1$ & $14 \cdot 3$ & $11 \cdot 6,17 \cdot 6$ & 0.553 \\
\hline Obesity (\%) & $3 \cdot 6$ & $2 \cdot 1,6 \cdot 1$ & $3 \cdot 8$ & $2 \cdot 6,5 \cdot 4$ & 0.890 \\
\hline Systolic BP (mmHg) & $116 \cdot 9$ & $115 \cdot 0,118 \cdot 8$ & $112 \cdot 6$ & $111 \cdot 1,114 \cdot 2$ & 0.001 \\
\hline Diastolic BP (mmHg) & $65 \cdot 6$ & $64 \cdot 3,66 \cdot 8$ & $68 \cdot 9$ & $65 \cdot 5,72 \cdot 3$ & 0.017 \\
\hline High BP (\%)t & $16 \cdot 9$ & $13 \cdot 1,21 \cdot 7$ & $12 \cdot 9$ & $9 \cdot 0,18 \cdot 0$ & 0.105 \\
\hline
\end{tabular}

BP, blood pressure.

*Leisure-time physical activity was defined as days per week the participant was physically active outside school.

tHigh BP is defined as $\geq 95$ th percentile. 
high BP ( $8 \cdot 4 \%)$ was also based on boys and girls combined. Our findings suggest important difference in BP between boys and girls. The prevalence rates found among adolescents in our study are relatively high compared with the rates found among younger age groups in Brazil. This indicates that high BP increases sharply with age and highlights the need for early intervention among children in Brazil.

The prevalence of high BP in our study is similar to the prevalence found among similar age groups (14-17 years) in Suriname, South America. In the Suriname study, the prevalence of high BP ranged from $9 \cdot 7 \%$ in Maroon boys to $18.8 \%$ in mixed race boys, and from $3.5 \%$ in Hindustani girls to $12 \cdot 0 \%$ in mixed race girls ${ }^{(35)}$. The mean systolic BP among Aracaju adolescent boys $(116.9 \mathrm{mmHg})$ was somewhat similar to that of Surinamese adolescent boys, except for Maroon boys $(112.5 \mathrm{mmHg}$ ) and Hindustani boys $(114.2 \mathrm{mmHg})$. The mean systolic BP was, however, higher in Aracaju girls $(112.6 \mathrm{mmHg})$ than in girls in Suriname in all ethnic groups, ranging from $104.5 \mathrm{mmHg}$ in Hindustani girls to $107.9 \mathrm{mmHg}$ in Creole girls ${ }^{(35)}$.

BP and obesity are strongly related ${ }^{(2,3,23-25)}$. Our present findings are in agreement with previous findings in Brazil $^{(20-22,36)}$. Although the mechanisms by which overweight and obesity may lead to high BP are not well elucidated, it is now generally recognised that overweight and obesity increase the risk of high $\mathrm{BP}^{(37)}$. Sinaiko et al.'s ${ }^{(37)}$ prospective study showed that increases in BMI in early life were significantly related to an increased risk of high BP and other CVD in adulthood. Our findings clearly indicate the need to prevent the increasing prevalence of overweight and obesity early in life to prevent future sequelae of overweight- and obesity-related diseases.

Several studies in children showed that weight loss results in a reduction of $\mathrm{BP}^{(23)}$. The recommended intervention strategy is a hypoenergetic diet plus physical activity $^{(38)}$. Increasing physical activity level in adolescents can be a low-cost intervention to prevent high BP. The physical activity level among adolescents in our study was relatively low. The international guideline for physical activity for children under 18 years of age recommends exercise of moderate intensity for at least $1 \mathrm{~h} / \mathrm{d}^{(7)}$. The average leisure-time physical activity was $3 \mathrm{~d} /$ week for boys and $2 \mathrm{~d}$ /week for girls in our study population, which is far less than the international guideline. The physical activity patterns were relatively low in normal-weight, overweight and obese individuals, with only small differences between the groups. This may explain why the result remained the same after adjustment for physical activity in the multivariate analyses. Similar low prevalence of physical activity has also been reported in other parts of Brazil. In a study in Maceio, Alagoas, the prevalence of a sedentary lifestyle, defined as no moderate-to-intense physical activity, was $93.5 \%$ in $7-17$-year-olds ${ }^{(39)}$. These findings clearly suggest that effective measures are urgently needed to increase physical activity level among adolescents in urban Brazil. 
(a)

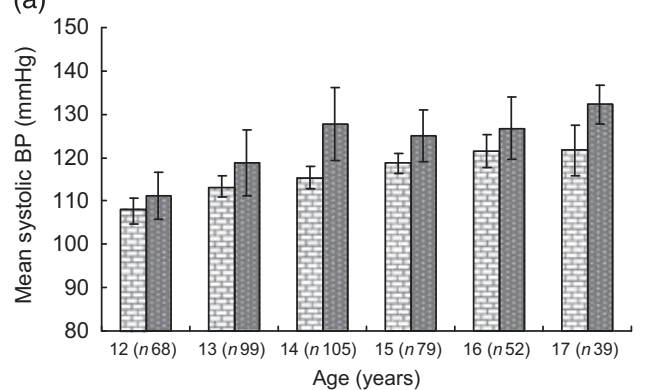

(b)

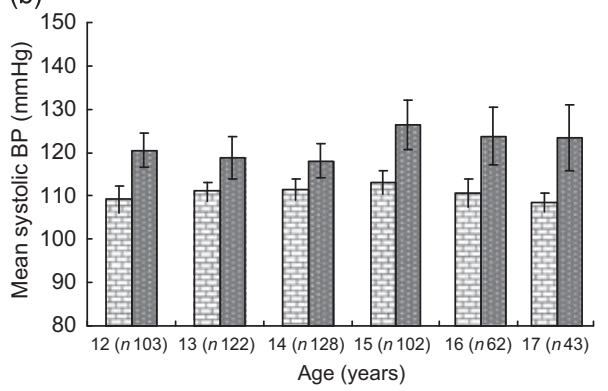

Fig. 1 Mean systolic blood pressure by BMl category and age in boys (a) and girls (b); 国, normal weight; 圄, overweight/obese

(a)

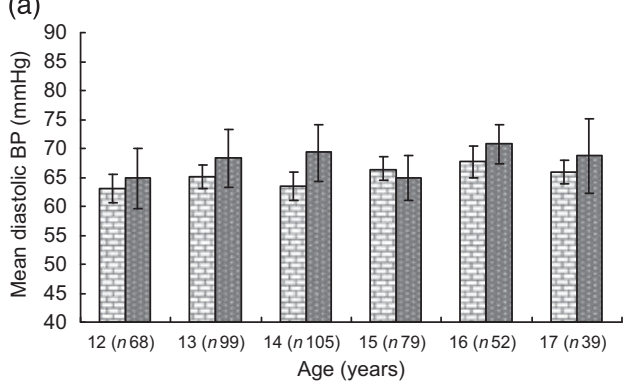

(b)

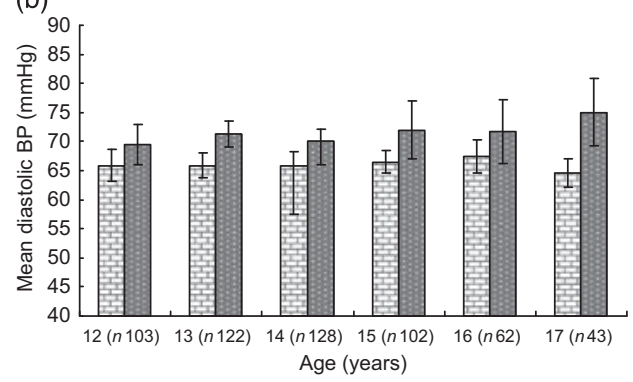

Fig. 2 Mean diastolic blood pressure by BMI category and age in boys (a) and girls (b); 国, normal weight; 专, overweight/obese

Table 3 Adjusted PR of high BP with corresponding $95 \% \mathrm{Cl}$ by body size and sex among Aracaju adolescents

\begin{tabular}{|c|c|c|c|c|c|c|c|c|}
\hline & \multirow[b]{2}{*}{$n$} & \multirow[b]{2}{*}{$\%$} & \multicolumn{2}{|c|}{ Model 1} & \multicolumn{2}{|c|}{ Model 2} & \multicolumn{2}{|c|}{ Model 3} \\
\hline & & & PR & $95 \% \mathrm{Cl}$ & PR & $95 \% \mathrm{Cl}$ & PR & $95 \% \mathrm{Cl}$ \\
\hline \multicolumn{9}{|l|}{ Boys } \\
\hline Normal weight & 371 & $14 \cdot 8$ & $1 \cdot 00$ & Ref. & $1 \cdot 00$ & Ref. & $1 \cdot 00$ & Ref. \\
\hline Overweight & 55 & $28 \cdot 2$ & $1 \cdot 80$ & $1 \cdot 02,3 \cdot 18$ & $1 \cdot 96$ & $1 \cdot 10,3 \cdot 50$ & $1 \cdot 93$ & $1 \cdot 08,3 \cdot 48$ \\
\hline Obese & 16 & $56 \cdot 2$ & 3.54 & $2 \cdot 03,6 \cdot 15$ & $4 \cdot 42$ & $2 \cdot 15,9 \cdot 09$ & $4 \cdot 87$ & $2 \cdot 35,10 \cdot 11$ \\
\hline \multicolumn{9}{|l|}{ Girls } \\
\hline Normal weight & 460 & $8 \cdot 5$ & $1 \cdot 00$ & Ref. & $1 \cdot 00$ & Ref. & $1 \cdot 00$ & Ref. \\
\hline Overweight & 77 & $33 \cdot 6$ & $4 \cdot 06$ & $2 \cdot 40,6 \cdot 86$ & $4 \cdot 27$ & $2 \cdot 52,7 \cdot 26$ & $4 \cdot 34$ & $2 \cdot 58,7 \cdot 30$ \\
\hline Obese & 22 & $38 \cdot 1$ & $4 \cdot 49$ & $2 \cdot 49,8.09$ & $5 \cdot 33$ & $2 \cdot 90,9 \cdot 82$ & $5 \cdot 18$ & $2 \cdot 67,10 \cdot 06$ \\
\hline
\end{tabular}

$\mathrm{PR}$, prevalence ratios; $\mathrm{BP}$, blood pressure; Ref., reference category.

Model 1, adjusted for age; model 2, plus type of school; model 3, plus physical activity.

\section{Limitations}

Our study has limitations. As in many epidemiological studies, our BP level was based on an average of three measurements at a single visit. A more precise estimate of BP level would be obtained by multiple measurements obtained during several visits ${ }^{(11)}$. The physical activity levels were based on only leisure-time exercise, and was self-reported, which may be subjected to response bias. We had no information on other important factors that are known to influence high BP, such as dietary behaviour, which may also affect our study conclusions. Also the non-response rate was high, particularly in the 12 -yearolds (43\%). It is possible that the health of the respondents and non-respondents may differ, which may affect our study conclusions. Nevertheless, the non-response rates were similar in both public $(32 \cdot 0 \%)$ and private
(33.6\%) schools. In addition, we corrected for the cluster design effect in the analyses. Furthermore, the distribution of boys and girls in our study is consistent with Aracaju's young population (male/female ratio: 47:53) ${ }^{(40)}$. Finally, our sample was based on Aracaju and its surroundings and therefore the findings may not be representative of other parts of Brazil. Despite these limitations, our present findings provide very important information on the relationship between overweight and obesity and BP among adolescents in Brazil.

In conclusion, our results show a high prevalence of high BP among this population in Brazil. Overweight and obesity were strongly associated with high BP in both boys and girls. Prevention strategies are needed in Brazil to prevent the future burden of hypertension and reduce pressure on the public health-care system. BP reductions 
in adolescents can be achieved by weight loss through reducing excessive energy intake ${ }^{(41)}$ and increasing physical activity strategies ${ }^{(42)}$. These cost-effective measures may lead to a significant reduction in BP in adolescents, thereby sparing the next generation from high BP-related complications.

\section{Acknowledgements}

The present research received no specific grant from any funding agency in the public, commercial or not-forprofit sectors. C.A. was supported by a VENI fellowship (Grant no. 916.76.130) awarded by the Board of the Council for Earth and Life Sciences (ALW) of the Netherlands Organisation for Scientific Research (NWO). The authors have no conflict of interest to declare. R.Q.G., J.P., R.R., R.E.d.O.R. and J.A.S.B.-F. were responsible for data collection; J.P., C.A., J.F.W., J.S.d.M. and R.Q.G. were responsible for analysis and interpretation of data; R.R. and C.A. drafted the manuscript and all were involved in critical revision of the manuscript. All authors were responsible for study concept and design.

\section{References}

1. Murray CJ \& Lopez AD (1997) Mortality by cause for eight regions of the world: global burden of disease study. Lancet 349, 1269-1276.

2. Muntner P, He J, Cutler JA et al. (2004) Trends in blood pressure among children and adolescents. JAMA 291, 2107-2113.

3. Falkner B, Gidding SS, Ramirez-Garnica G et al. (2006) The relationship of body mass index and blood pressure in primary care pediatric patients. J Pediatr 148, 195-200.

4. Chobanian AV, Bakris GL, Black HR et al. (2003) Seventh report of the Joint National Committee on Prevention, Detection, Evaluation, and Treatment of High Blood Pressure. Hypertension 42, 1206-1252.

5. Ala L, Gill G, Gurgel R et al. (2004) Evidence for affluencerelated hypertension in urban Brazil. J Hum Hypertens $\mathbf{1 8}$, 775-779.

6. Ordunez P, Silva LC, Rodriguez MP et al. (2001) Prevalence estimates for hypertension in Latin America and the Caribbean: are they useful for surveillance? Pan. Am J Public Health 10, 226-231.

7. World Health Organization (2008) World health statistics. http://www.who.int/countries/bra/en/ (accessed February 2009).

8. Bao W, Threefoot SA, Srinivasan SR et al. (1995) Essential hypertension predicted by tracking of elevated blood pressure from childhood to adulthood: The Bogalusa Heart Study. Am J Hypertens 8, 657-665.

9. Lauer RM \& Clarke WR (1989) Childhood risk factors for high adult blood pressure: The Muscatine Study. Pediatrics 84, 633-641.

10. Daniels SR, Loggie JM, Khoury P et al. (1998) Left ventricular geometry and severe left ventricular hypertrophy in children and adolescents with essential hypertension. Circulation 97, 1907-1911.

11. National High Blood Pressure Education Program Working Group on High Blood Pressure in Children and Adolescents (2004) The fourth report on the diagnosis, evaluation, and treatment of high blood pressure in children and adolescents. Pediatrics 114, Suppl. 2, 555-576.
12. Sorof JM, Lai D, Turner J et al. (2004) Overweight, ethnicity, and the prevalence of hypertension in school-aged children. Pediatrics 113, 475-482.

13. Paradis G, Lambert M, O'Loughlin J et al. (2004) Blood pressure and adiposity in children and adolescents. Circulation 110, 1832-1838.

14. Genovesi S, Giussani M, Pieruzzi F et al. (2005) Results of blood pressure screening in a population of school-aged children in the province of Milan: role of overweight. J Hypertens 23, 493-497.

15. Jafar TH, Islam M, Poulter N et al. (2005) Children in South Asia have higher body mass-adjusted blood pressure levels than white children in the United States: a comparative study. Circulation 111, 1291-1297.

16. Proctor MH, Moore LL, Singer MR et al. (1996) Risk profiles for noncommunicable diseases in rural and urban schoolchildren in the Republic of Cameroon. Ethn Dis $\mathbf{6}$, 235-243.

17. Agyemang C, Redekop WK, Owusu-Dabo E et al. (2005) Blood pressure patterns in rural, semi-urban and urban children in the Ashanti region of Ghana, West Africa. BMC Public Health 5, 114.

18. Monyeki KD, Kemper HC \& Makgae PJ (2006) The association of fat patterning with blood pressure in rural South African children: The Ellisras Longitudinal Growth and Health Study. Int J Epidemiol 35, 114-120.

19. Chiolero A, Madeleine G, Gabriel A et al. (2007) Prevalence of elevated blood pressure and association with overweight in children of a rapidly developing country. J Hum Hypertens 21, 120-127.

20. Guimarães IC, de Almeida AM, Santos AS et al. (2008) Blood pressure: effect of body mass index and of waist circumference on adolescents. Arq Bras Cardiol 90, 393-399.

21. Rodrigues AN, Moyses MR, Bissoli NS et al. (2006) Cardiovascular risk factors in a population of Brazilian schoolchildren. Braz J Med Biol Res 39, 1637-1642.

22. Costanzi CB, Halpern R, Rech RR et al. (2009) Associated factors in high blood pressure among schoolchildren in a middle size city, southern Brazil. J Pediatr (Rio J) 85, 335-340.

23. Torrance B, McGuire KA, Lewanczuk R et al. (2007) Overweight, physical activity and high blood pressure in children: a review of the literature. Vasc Health Risk Manag 3, 139-149.

24. Aristimuño GG, Foster TA, Voors AW et al. (1984) Influence of persistent obesity in children on cardiovascular risk factors: The Bogalusa Heart Study. Circulation 69, 895-904.

25. Weiss R, Dziura J, Burgert TS et al. (2004) Obesity and the metabolic syndrome in children and adolescents. $N$ Engl $J$ Med 350, 2362-2374.

26. Ford ES, Mokdad AH \& Ajani UA (2004) Trends in risk factors for cardiovascular disease among children and adolescents in the United States. Pediatrics 114, 1534-1544.

27. Watkins D, McCarron P, Murray L et al. (2004) Trends in blood pressure over 10 years in adolescents: analyses of cross sectional surveys in the Northern Ireland Young Hearts project. BMJ 329, 139.

28. Mendonça da Silva MA, Romero Rivera I, Goretti Barbosa de Souza M et al. (2007) Blood pressure measurement in children and adolescents: guidelines of high blood pressure recommendations and current clinical practice. Arq Bras Cardiol 88, 491-495.

29. Brazilian Institute of Geography and Statistics (2006) Family Budget Survey 2002-2003. Atbropometric and Nutritional Status Analysis in Brazil. Rio de Janeiro: IBGE.

30. Nobre MR, Domingues RZ, da Silva AR et al. (2006) Prevalence of overweight, obesity and life style associated with cardiovascular risk among middle school students. Rev Assoc Med Bras 52, 118-124. 
31. Parati G, Stergiou GS, Asmar R et al. (2008) ESH Working Group on Blood Pressure Monitoring. European Society of Hypertension guidelines for blood pressure monitoring at home: a summary report of the Second International Consensus Conference on Home Blood Pressure Monitoring. J Hypertens 26, 1505-1526.

32. Centers for Disease Control and Prevention (2000) CDC clinical growth charts. http://www.cdc.gov/growthcharts/ (accessed December 2008).

33. Cole TJ, Bellizzi MC, Flegal KM et al. (2000) Establishing a standard definition for child overweight and obesity worldwide: international survey. BMJ 320, 1240-1243.

34. Barros AJ \& Hirakata VN (2003) Alternatives for logistic regression in cross-sectional studies: an empirical comparison of models that directly estimate the prevalence ratio. BMC Med Res Methodol 3, 21.

35. Agyemang C, Oudeman E, Zijlmans W et al. (2009) Blood pressure and body mass index in an ethnically diverse sample of adolescents in Paramaribo, Suriname. BMC Cardiovasc Disord 9, 19.

36. Campana EM, Brandao AA, Pozzan R et al. (2009) Blood pressure in young individuals as a cardiovascular risk marker. The Rio de Janeiro Study. Arq Bras Cardiol 93, 608-615.
37. Sinaiko AR, Donahue RP, Jacobs DR Jr et al. (1999) Relation of weight and rate of increase in weight during childhood and adolescence to body size, blood pressure, fasting insulin, and lipids in young adults. The Minneapolis Children's Blood Pressure Study. Circulation 99, $1471-1476$.

38. Ribeiro MM, Silva AG, Santos NS et al. (2005) Diet and exercise training restore blood pressure and vasodilatory responses during physiological maneuvers in obese children. Circulation 111, 1915-1923.

39. Silva MA, Rivera IR, Ferraz MR et al. (2005) Prevalence of cardiovascular risk factors in child and adolescent students in the city of Maceió. Arq Bras Cardiol 84, 387-392.

40. Abdelgalil S, Gurgel RG, Theobald S et al. (2004) Household and family characteristics of street children in Aracaju, Brazil. Arch Dis Child 89, 817-820.

41. Gallist S, Sudi KM, Aigner R et al. (2001) Changes in serum interleukin- 6 concentrations in obese children and adolescents during a weight reduction program. Int J Obes Relat Metab Disord 25, 1640-1643.

42. Rocchini A, Katch V, Anderson J et al. (1988) Blood pressure in obese adolescents: effect of weight loss. Pediatrics 82, 16-23. 